\title{
Interaction of gypsum and the rhizome of Anemarrhena asphodeloides plays an important role in anti-allergic effects of byakkokakeishito in mice
}

\author{
Toshiaki Makino $\cdot$ Yusaku Shiraki • \\ Hajime Mizukami
}

Received: 17 December 2013/ Accepted: 7 February 2014/Published online: 20 February 2014

(C) The Japanese Society of Pharmacognosy and Springer Japan 2014

\begin{abstract}
Gypsum is a crude mineral drug used in the formulas of Japanese kampo medicine and traditional Chinese medicine. The present study aimed to evaluate the anti-allergic effect of byakkokakeishito extract (BKT), which consists of gypsum (natural hydrous calcium sulfate), Anemarrhena Rhizome (rhizome of Anemarrhena asphodeloides), Cinnamon Bark (bark of trunk of Cinnamomum cassia), Oriza Seed (seed of Oryza sativa), and Glycyrrhiza (root and stolon of Glycyrrhiza uralensis), and to clarify the role of gypsum in the formula. We prepared BKT by boiling a mixture of various quantities of gypsum and fixed amounts of the other four crude drugs in water. We evaluated the anti-allergic activity of the formulations using three different murine models of allergy: contact dermatitis induced by painting hapten onto skin; allergic dermatitis-like symptoms induced by cutaneous injection of mite-antigen; and skin passive cutaneous anaphylaxis (PCA) reaction using ovalbumin as antigen. The calcium content in the various BKT samples was dose-dependently increased up to $60 \mathrm{~g} /$ day of human dosage. BKT significantly suppressed the allergic symptoms in the three different experimental models. The effect of BKT was augmented by increasing the gypsum dosage only in the PCA reaction model. The extract prepared from a mixture of Anemarrhena Rhizome and gypsum exhibited an effect comparable to that of BKT. BKT exhibits an anti-allergic effect in several animal models, which may provide experimental evidence for the clinical use of BKT in allergic diseases. Gypsum may augment the anti-allergic
\end{abstract}

T. Makino $(\bowtie) \cdot$ Y. Shiraki $\cdot$ H. Mizukami Department of Pharmacognosy, Graduate School of Pharmaceutical Science, Nagoya City University, 3-1 Tanabe-Dori, Mizuho-ku, Nagoya 4678603, Japan e-mail: makino@phar.nagoya-cu.ac.jp activity of BKT, presumably through increasing intestinal absorption of Anemarrhena Rhizome-derived active constituents.

Keywords Gypsum · Anemarrhena rhizome - Kampo medicine $\cdot$ Allergic diseases $\cdot$ Calcium

\section{Introduction}

Gypsum is a crude mineral drug used in traditional Japanese kampo medicine and traditional Chinese medicine. In the Japanese Pharmacopoeia XVI Edition (JPXVI) [1], gypsum is defined as natural hydrous calcium sulfate and is prescribed in 13 of the over-the-counter kampo formulas permitted by the Ministry of Health, Labour and Welfare of Japan. According to the theory of kampo medicine, gypsum clears "heat", drains "fire", and promotes "fluid" production, which leads to treatment of symptoms including profuse sweating, oral dryness, severe thirst, feeling of heat or burning skin, and itching [2]. Ikarashi et al. [3] reported that in mice given a diet containing $0.3 \%$ gypsum powder for 4 weeks, the expression levels of aquaporin 3 mRNA and protein in the skin were increased. Since aquaporin 3 plays an important role in maintaining skin hydration, the traditional usage of gypsum may be related to this pharmacological effect.

In kampo medicine, prescribed crude drugs in formulas are mostly boiled in water, and the resulting decoction is administered to the patient after removing the residues by filtration. Since the solubility of $\mathrm{CaSO}_{4}$ in water is low $\left(\sim 1.6 \mathrm{~g} / \mathrm{l}\right.$ at $\left.100{ }^{\circ} \mathrm{C}\right)$ and since gypsum contains few organic compounds, the pharmacological role of gypsum prescribed in kampo formulas remains unknown, and some researchers have attempted to solve it. There have been 
some reports describing the interaction of gypsum with other crude drugs prescribed together in kampo formulas. For example, gypsum counteracted the thermogenous effect of Ephedra Herb (terrestrial stem of Ephedra sinica) when administered simultaneously to rats [4]. The suppressive effect of byakkokaninjinto, a kampo formula consisting of Gypsum and four other crude drugs, on immunoglobulin E (IgE)-mediated triphasic skin reaction in mice disappeared when gypsum was removed from the formula [5]. It was also reported that gypsum affected the extraction efficiency of organic compounds from the crude drugs prescribed in the formula. When chotosan, a kampo formula containing gypsum, Uncaria Hook (hook of Uncaria rhynchophylla), and nine other crude drugs, was decocted without gypsum, the content of alkaloids derived from Uncaria Hook in the filtered decoction was significantly decreased [6]. In makyokansekito, a kampo formula containing gypsum, Ephedra Herb, Apricot Kernel (seed of Prunus armeniaca), and Glycyrrhiza (root and stolon of Glycyrrhiza uralensis), the elution of alkaloids from Ephedra Herb significantly decreased when the formula was boiled without gypsum [7].

The dosage of gypsum administered as kampo formulas is usually $5-15 \mathrm{~g} /$ day. However, physicians using kampo medicines have found clinically that a much higher gypsum dosage markedly enhances the "heat"-clearing effect of the kampo formula. Imai et al. [8] reported that inflammatory skin lesions in patients with atopic dermatitis recovered when the gypsum dosage was increased from 15 to $100 \mathrm{~g} /$ day in byakkokakeishito. However, there is no experimental evidence for the anti-allergic effects of byakkokakeishito or for the effectiveness of increasing the gypsum dosage in byakkokakeishito.

In the present study, we compared the anti-allergic activities of byakkokakeishito extracts (BKTs) prepared with varied amounts of gypsum to clarify the pharmacological role of gypsum in kampo formulas using three different murine models of allergy: contact dermatitis induced by painting hapten onto skin; allergic dermatitis induced by cutaneous injection of mite antigen; and skin passive cutaneous anaphylaxis (PCA) reaction using ovalbumin (OVA) as antigen.

\section{Materials and methods}

Preparation of herbal formulas

Gypsum (lot No. 7H16 M, natural hydrous calcium sulfate), Anemarrhena Rhizome (0E22, the rhizome of Anemarrhena asphodeloides), Cinnamon Bark (6K20 M, the bark of the trunk of Cinnamomum cassia, Chinese cinnamon), and Oriza Seed (5G29, the seed of Oryza
Table 1 Components of crude drugs in various byakkokakeishito extract $(B K T)$ samples

\begin{tabular}{|c|c|c|c|c|c|}
\hline & $\mathrm{BKT0}^{\mathrm{a}}$ & BKT7.5 & $\mathrm{BKT} 15^{\mathrm{b}}$ & BKT30 & BKT60 \\
\hline Gypsum & - & $7.5 \mathrm{~g}^{\mathrm{c}}$ & $15 \mathrm{~g}$ & $30 \mathrm{~g}$ & $60 \mathrm{~g}$ \\
\hline Oriza seed & $8.0 \mathrm{~g}$ & $8.0 \mathrm{~g}$ & $8.0 \mathrm{~g}$ & $8.0 \mathrm{~g}$ & $8.0 \mathrm{~g}$ \\
\hline $\begin{array}{l}\text { Anemarrhena } \\
\text { rhizome }\end{array}$ & $5.0 \mathrm{~g}$ & $5.0 \mathrm{~g}$ & $5.0 \mathrm{~g}$ & $5.0 \mathrm{~g}$ & $5.0 \mathrm{~g}$ \\
\hline Cinnamon bark & $4.0 \mathrm{~g}$ & $4.0 \mathrm{~g}$ & $4.0 \mathrm{~g}$ & $4.0 \mathrm{~g}$ & $4.0 \mathrm{~g}$ \\
\hline Glycyrrhiza & $2.0 \mathrm{~g}$ & $2.0 \mathrm{~g}$ & $2.0 \mathrm{~g}$ & $2.0 \mathrm{~g}$ & $2.0 \mathrm{~g}$ \\
\hline Ratio of yield ${ }^{\mathrm{d}}$ & $18.3 \%$ & $14.8 \%$ & $13.2 \%$ & $9.4 \%$ & $6.0 \%$ \\
\hline $\begin{array}{l}\text { Daily dosage } \\
\text { of extract } \\
\text { administered } \\
\text { to mice }\end{array}$ & $0.70 \mathrm{~g} / \mathrm{kg}$ & - & $0.90 \mathrm{~g} / \mathrm{kg}$ & - & $\begin{array}{c}0.95 \mathrm{~g} / \\
\mathrm{kg}\end{array}$ \\
\hline
\end{tabular}

\footnotetext{
${ }^{a}$ Name of the extract prepared by decocting a mixture of four or five crude drugs as shown in the Table

b This formula is recognized as the standard byakkokakeishito formula in the textbook of kampo medicine [9]

c Weight of each crude drug when administered at the human daily dosage

${ }^{d}$ Ratio of yield of the extract calculated as \% of dried weight of the extract to the weight of a mixture of crude drugs

e Calculated as ten times the human daily dosage. For example, for BKT15, sum of crude drugs $(34 \mathrm{~g})$ times ratio of yield $(13.2 \%)$ divided by human body weight $(50 \mathrm{~kg}) \times 10=0.898 \mathrm{~g} / \mathrm{kg}=0.90 \mathrm{~g} /$ $\mathrm{kg}$
}

sativa, Asian rice) were purchased from Daiko Shoyaku (Nagoya, Japan), and Glycyrrhiza (23040711, the root and stolon of Glycyrrhiza uralensis, Chinese liquorice) was from Tsumura (Tokyo, Japan). These crude drugs were of JPXVI grade and used as small pieces prepared by cutting or crushing of the whole crude drugs. The voucher specimens are deposited in our laboratory.

Tables 1 and 2 show the components of BKT samples used in the present study. The standard gypsum dosage administered as BKT is $15 \mathrm{~g} /$ day according to an authentic textbook on kampo medicine [9]. The crude drugs corresponding to their daily dosage were packed together in paper bags and boiled in $600 \mathrm{ml}$ of distilled water for $60 \mathrm{~min}$. The crude drugs were then removed from the paper bags, and the decoctions were lyophilized. The dried extracts were stored at room temperature in a desiccator until use. Tables 1 and 2 also show the yields of the extracts.

Determination of calcium in BKT samples

The lyophilized BKT samples $(10 \mathrm{mg})$ were dissolved in $100 \mathrm{ml}$ distilled water, and the calcium concentrations were measured using an atomic absorption photometer (AA-660, Shimadzu, Kyoto, Japan). The measurement was repeated three times, and data are represented as mean \pm S.E. 
Table 2 Components of crude drugs in the various byakkokakeishito extracts (BKT)

\begin{tabular}{|c|c|c|c|c|c|c|c|c|}
\hline & BKT60 ${ }^{\mathrm{a}}$ & BKT-O & BKT-A & BKT-C & BKT-G & A & $\mathrm{A}+\mathrm{G} 60$ & G60 \\
\hline Gypsum (G) & $60 \mathrm{~g}^{\mathrm{b}}$ & $60 \mathrm{~g}$ & $60 \mathrm{~g}$ & $60 \mathrm{~g}$ & $60 \mathrm{~g}$ & - & $60 \mathrm{~g}$ & $60 \mathrm{~g}$ \\
\hline Oriza seed $(\mathrm{O})$ & $8.0 \mathrm{~g}$ & - & $8.0 \mathrm{~g}$ & $8.0 \mathrm{~g}$ & $8.0 \mathrm{~g}$ & - & - & - \\
\hline Anemarrhena rhizome (A) & $5.0 \mathrm{~g}$ & $5.0 \mathrm{~g}$ & - & $5.0 \mathrm{~g}$ & $5.0 \mathrm{~g}$ & $5.0 \mathrm{~g}$ & $5.0 \mathrm{~g}$ & - \\
\hline Cinnamon bark (C) & $4.0 \mathrm{~g}$ & $4.0 \mathrm{~g}$ & $4.0 \mathrm{~g}$ & - & $4.0 \mathrm{~g}$ & - & - & - \\
\hline Glycyrrhiza (G) & $2.0 \mathrm{~g}$ & $2.0 \mathrm{~g}$ & $2.0 \mathrm{~g}$ & $2.0 \mathrm{~g}$ & - & - & - & - \\
\hline Ratio of yield ${ }^{c}$ & $6.0 \%$ & $6.1 \%$ & $3.6 \%$ & $5.2 \%$ & $6.0 \%$ & $45.2 \%$ & $5.1 \%$ & $0.90 \%$ \\
\hline Dosage of extract administered to mice ${ }^{\mathrm{d}}$ & $0.47 \mathrm{~g} / \mathrm{kg}$ & $0.43 \mathrm{~g} / \mathrm{kg}$ & $0.27 \mathrm{~g} / \mathrm{kg}$ & $0.39 \mathrm{~g} / \mathrm{kg}$ & $0.46 \mathrm{~g} / \mathrm{kg}$ & $0.23 \mathrm{~g} / \mathrm{kg}$ & $0.33 \mathrm{~g} / \mathrm{kg}$ & $0.054 \mathrm{~g} / \mathrm{kg}$ \\
\hline
\end{tabular}

\footnotetext{
${ }^{a}$ Name of the extract prepared by decocting a mixture of four or five crude drugs as shown in the Table

b Weight of each crude drug when administered at the human daily dosage

${ }^{c}$ Ratio of yield of the extract calculated as \% of dried weight of the extract to the weight of a mixture of crude drugs

${ }^{\mathrm{d}}$ Calculated as five times the human daily dosage. For example, for BKT60, sum of crude drugs $(79 \mathrm{~g})$ times ratio of yield (6.0 \%) divided by human body weight $(50 \mathrm{~kg}) \times 5=0.47 \mathrm{~g} / \mathrm{kg}$
}

\section{HPLC analysis}

An amount of each BKT sample corresponding to $1 \%$ of the human daily dosage was sonicated in $\mathrm{MeOH}(5 \mathrm{ml})$ for $30 \mathrm{~min}$ and centrifuged at $12,000 \mathrm{~g}$ for $7 \mathrm{~min}$. The supernatant fraction $(25 \mu \mathrm{l})$ was subjected to HPLC analysis using the following conditions: system, Shimadzu LC$10 \mathrm{~A}_{\mathrm{VP}}$; column, TSK-GEL ODS- $80_{\mathrm{TS}}(4.6 \times 250 \mathrm{~mm}$; Tosoh, Tokyo, Japan); mobile phase, $0.05 \mathrm{M} \mathrm{AcONH}_{4}(\mathrm{pH}$ 3.6) $/ \mathrm{CH}_{3} \mathrm{CN} 90: 10 \rightarrow 45: 55(0 \rightarrow 30 \mathrm{~min})$, linear gradient; flow rate, $1.0 \mathrm{ml} / \mathrm{min}$; column temperature, $40{ }^{\circ} \mathrm{C}$; detection, $200-400 \mathrm{~nm}$ using a photodiode array detector. Peaks were identified on the basis of the comparison with the retention times and UV spectra of authentic compounds.

\section{Quantitative analysis of timosaponin A-III}

An amount of each BKT sample corresponding to $4 \%$ of the human daily dosage was sonicated in $\mathrm{MeOH}(40 \mathrm{ml})$ for $30 \mathrm{~min}$. A 100- $\mu \mathrm{l}$ aliquot of the sample or the standard solution of timosaponin A-III (Wako Pure Chemicals, Osaka, Japan) was mixed with $100 \mu \mathrm{l} \mathrm{MeOH}$ containing $1 \mathrm{ng} / \mathrm{ml}$ astragaloside IV (Wako Pure Chemicals) as an internal standard. Timosaponin A-III concentration was determined using an LC/MS/MS system (Waters Quattro Premier XE; Milford, MA, USA) with an electrospray ionization source in the positive ion mode and multiple reaction monitoring. HPLC separation was performed under the following conditions: column, Inertosil ODS-3 $(4.6 \times 250 \mathrm{~mm}$, GL Science, Tokyo, Japan); mobile phase, a linear gradient elution system, $0.1 \% \mathrm{AcOH}$ in $\mathrm{H}_{2} \mathrm{O}$ (solvent A): $0.1 \% \mathrm{AcOH}$ in acetonitrile (solvent B) (B/ A) $=40 / 60 \rightarrow 40 / 60$ for $0 \rightarrow 2 \mathrm{~min}$; 40/60 $\rightarrow$ 90/10 for $2 \rightarrow 4 \mathrm{~min} ; 90 / 10 \rightarrow 90 / 10$ for $4 \rightarrow 6 \mathrm{~min}$ at a flow rate of $200 \mu \mathrm{l} / \mathrm{min}$. The injection volume of the sample was
$10 \mu \mathrm{l}$. Both quadrupoles were maintained at the unit resolution and the transitions (precursor to daughter) monitored were $m / z, 741.5-84.8$ for timosaponin A-III (retention time, $5.5 \mathrm{~min}$ ) and $\mathrm{m} / \mathrm{z} .785 .4-143.0$ for astragaloside IV (2.8 $\mathrm{min})$. Linear regression in a concentration range of $0.1-5 \mathrm{ng} / \mathrm{ml}$ for timosaponin A-III was calibrated by the peak area ratio of these compounds to astragaloside IV by the least-squares method $\left(r^{2}>0.999\right)$.

\section{Animal experiments}

Balb/c and ddY mice were purchased from Japan SLC (Hamamatsu, Japan). NC/Jic mice were obtained from Clea Japan Inc. (Tokyo, Japan). They were housed in a temperature-controlled room (at $23 \pm 1{ }^{\circ} \mathrm{C}$ ) with lighting from 7 a.m. to 7 p.m. and allowed free access to food (CE-2; Oriental Yeast, Tokyo, Japan) and water under conventional conditions. Lyophilized BKT samples were suspended in distilled water at prescribed concentrations and orally administered to mice. The experimental procedures were approved by the Animal Care Committee in Graduate School of Pharmaceutical Sciences, Nagoya City University.

\section{Contact dermatitis model}

The contact dermatitis model was prepared according to the method of Yamashita et al. [10] with slight modifications. Male Balb/c mice (6-7 weeks old) were initially sensitized by painting $100 \mu \mathrm{l}$ of 2,4,6-trinitrochlorobenzene (TNCB; Nacalai Tesque, Kyoto, Japan) solution in acetone $(50 \mathrm{mg} / \mathrm{ml})$ onto their abdomens. 7 days after sensitization, the mice were challenged by painting $10 \mu \mathrm{l}$ of TNCB solution in olive oil $(10 \mathrm{mg} / \mathrm{ml})$ on both sides of their right ears. In the normal group, each vehicle was painted on murine abdomens and ears. The thicknesses of 
both ears were measured using a dial thickness gauge (Peacok model G-1A, Ozaki MFJ; Tokyo, Japan) 24 h after challenge, and data are expressed as the difference in the thickness of the two ears. The BKT samples were suspended in water and administered once a day from 3 days before until 6 days after sensitization.

Mite antigen-induced atopic dermatitis-like skin lesion model

The model was prepared as described previously [11]. In brief, Dermatophagoides farinae allergenic extract (Greer, Lenoir, NC, USA) (mite antigen) was diluted to $1 \mathrm{mg} / \mathrm{ml}$ in saline, and intracutaneously injected into the right ears of the mice (10 $\mu \mathrm{l} /$ ear) on days 0 (first injection), 2, 4, 7, 9, 11, 14, and 16 . The BKT samples were suspended in water and orally administered to the mice once a day from 7 days before until 16 days after the first injection. Ear thickness was measured using a dial thickness gauge 1 and $24 \mathrm{~h}$ after injection, and data are expressed as the difference from the values before the first injection. The mice were killed by $\mathrm{CO}_{2}$ inhalation on day 17 , and blood was collected. The area under the curve (AUC) from day 0 to day 17 after the first injection was calculated using the trapezoidal rule. IgE in the serum was measured by sandwich enzyme-linked immunosorbent assay.

\section{PCA reaction model}

The PCA reaction model was prepared as described previously [12]. In brief, OVA (Seikagaku Corporation, Tokyo, Japan) was suspended in $20 \mathrm{mg} / \mathrm{ml} \mathrm{Al}(\mathrm{OH})_{3}$ solution (final concentration of OVA, $10 \mu \mathrm{g} / \mathrm{ml}$ ), and $0.2 \mathrm{ml}$ of this suspension (OVA, $2 \mu \mathrm{g}$ ) was injected intraperitoneally into 4-week-old female Balb/c mice five times at 2-week intervals. 10 days after the fifth injection of OVA, whole blood was collected to obtain anti-OVA serum. A $10-\mu 1$ aliquot of 30-fold diluted anti-OVA serum was injected intracutaneously into each ear of 6-week-old male ddY mice After $48 \mathrm{~h}$, OVA (10 mg/kg body weight) in saline containing $0.5 \%$ Evans blue (Wako Pure Chemicals) was injected intravenously to induce PCA reaction (antigen challenge). The BKT samples were suspended in water and administered orally to overnight-fasted mice $2 \mathrm{~h}$ before antigen challenge. The mice were killed by cervical dislocation $30 \mathrm{~min}$ after the antigen challenge. Their ears were removed, immersed in $0.3 \mathrm{ml}$ of $1 \mathrm{M} \mathrm{KOH}$ overnight at $37{ }^{\circ} \mathrm{C}$, and Evans blue in the ears was extracted with $0.7 \mathrm{ml}$ of acetone/3.3 M phosphoric acid (67:3). Evans blue concentration was measured colorimetrically at $620 \mathrm{~nm}$. Data are expressed as quantity of Evans blue per gram fresh weight of ears.
Statistical analyses

Statistical analyses were performed by repeated one-way analysis of variance and Bonferroni/Dunnett's multiple $t$ test using PASW Statistics (version 18, SPSS; IBM, Armonk, NY, USA). A probability value $<0.05$ was considered statistically significant.

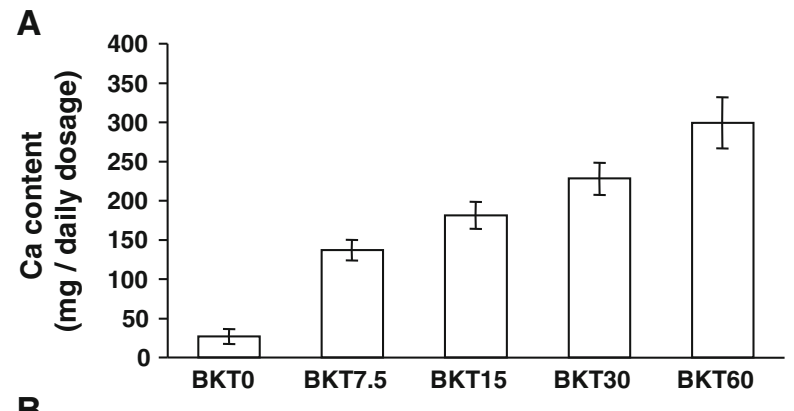

B
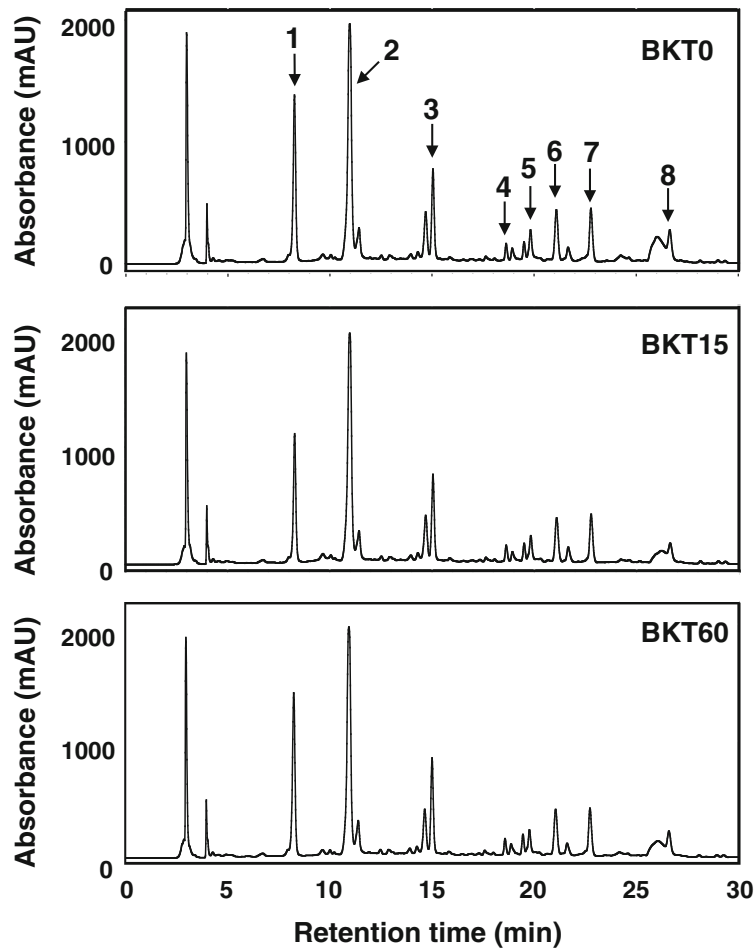

Fig. 1 Calcium content (a) and HPLC chromatograms (b) of byakkokakeishito extracts (BKTs) containing different contents of gypsum. a Modified BKT samples were prepared by decocting crude drugs as shown in Table 1, and calcium contents were measured. Each column represents mean \pm S.E. of three samples. b Each BKT sample was dissolved in $\mathrm{MeOH}$ and analyzed by HPLC as described in "Materials and Methods". Chromatograms are shown as the wavelength at $254 \mathrm{~nm}$. Peaks were identified as mangiferin-7- $O$ glucoside (1), mangiferin (2), liquiritin (3), glycyroside (4), isoliquiritin (5), liquiritigenin (6), glycyrrhizin (7), and cinnamaldehyde $(8)$ 


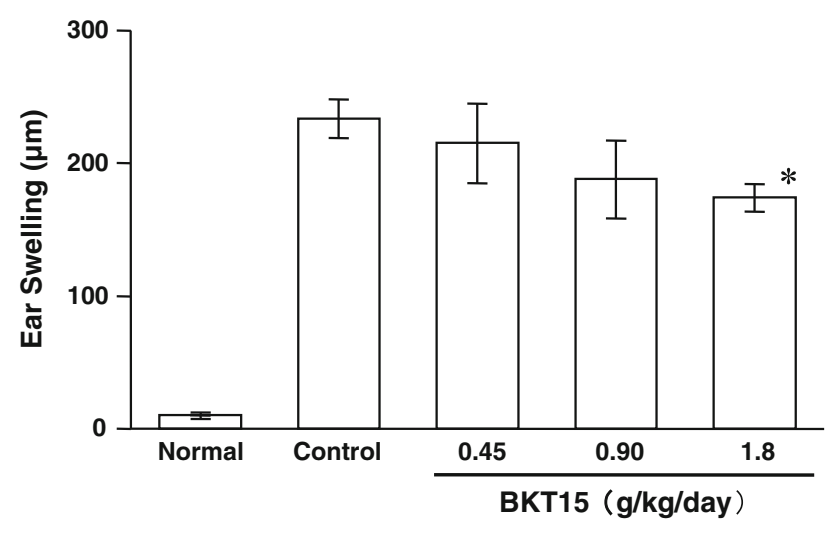

Fig. 2 Effect of byakkokakeishito extracts (BKTs) on 2,4,6-trinitrochlorobenzene $(T N C B)$-induced contact hypersensitivity in male $\mathrm{Balb} / \mathrm{c}$ mice. Ear swelling was measured $24 \mathrm{~h}$ after the sensitization. The daily dosage of BKT15 $(0.90 \mathrm{~g} / \mathrm{kg})$ corresponds to ten times that of the human daily dose. Each column represents mean \pm S.E. of 8 mice. ${ }^{*} p<0.05$ vs. control by Bonferroni/Dunnett's multiple $t$ test

\section{Results}

Constituents of BKT samples

Various BKT samples were prepared by changing the amount of gypsum (Table 1). The BKT sample prepared in order to provide the equivalent of the human daily dosage of gypsum (15 g/day) was recognized as a standard in a textbook of kampo medicine. The calcium content in the BKT samples increased as gypsum content increased (Fig. 1a). No apparent differences in HPLC profiles were observed between the BKT samples prepared with various amounts of gypsum (Fig. 1b). The amount of gypsum present in BKT did not affect the timosaponin A-III content, and BKT prepared without gypsum (BKT0), BKT15, and BKT prepared with $60 \mathrm{~g} / \mathrm{kg}$ of gypsum (BKT60) contained 3.56, 3.43, and $3.39 \mathrm{mg}$ of timosaponin A-III, respectively, in the amount of human daily dosage.

\section{Contact dermatitis model}

Daily oral administration of BKT15 significantly suppressed ear swelling induced by TNCB in a dose-dependent manner (Fig. 2). We then compared the effect of modified BKT samples containing varying amounts of gypsum. The BKT samples were administered orally to mice at dosages corresponding to the BKT15 dosage $(0.9 \mathrm{~g} / \mathrm{kg} /$ day $)$. The suppressive effects of BKT on the contact dermatitis model were not significantly different between the BKT samples containing different amounts of gypsum, and gypsum itself did not show any effects on murine contact dermatitis (data not shown).
Mite antigen-induced atopic dermatitis-like skin lesion model

Daily oral administration of BKT15 resulted in a significant decrease in ear swelling on days 15 and 17 after the first injection of the mite antigen (Fig. 3a), and BKT15 $(0.90 \mathrm{~g} / \mathrm{kg} /$ day $)$ significantly suppressed the level of ear swelling evaluated as AUC from day 0 to day 17 (Fig. 3b). BKT15 suppressed serum IgE levels on day 17 in a dosedependent manner, and mice treated with BKT15 (0.90 g/ $\mathrm{kg} /$ day) exhibited a significant difference (Fig. 3c). We then compared the effect of modified BKT samples containing varying amounts of gypsum at a dosage corresponding to the BKT15 dosage $(0.90 \mathrm{~g} / \mathrm{kg} /$ day $)$. The suppressive effects on ear swelling and serum IgE levels were not significantly different between the BKT samples containing varying amounts of gypsum (data not shown).

PCA reaction model

A single oral administration of BKT15 to mice significantly suppressed the ear PCA reaction in a dose-dependent manner (Fig. 4a). We then compared the effect of BKT containing varying amounts of gypsum at a dosage corresponding to the BKT15 dosage $(0.45 \mathrm{~g} / \mathrm{kg})$. BKT0 did not suppress the PCA reaction, while BKT60 significantly reduced dye elution in the ears of mice (Fig. 4b).

We prepared modified BKT60 samples by removing one crude drug from the byakkokakeishito formula at a dosage corresponding to the BKT60 dosage $(0.47 \mathrm{~g} / \mathrm{kg} / \mathrm{day})$ (Table 2). BKT60 prepared without Oriza Seed exhibited a suppressive effect similar to that shown by the original BKT60. BKT60 prepared without Cinnamon Bark or Glycyrrhiza exhibited slightly less suppressive effect compared with the original BKT60. BKT60 prepared without Anemarrhena Rhizome lost its suppressive effect on the PCA reaction, and the dye elution was same as that in the control group (Fig. 4c). Although neither Anemarrhena Rhizome nor gypsum significantly suppressed the PCA reaction, the extract prepared from a mixture of Anemarrhena Rhizome and gypsum exhibited an effect comparable to that of BKT60 (Fig. 4d).

\section{Discussion}

In the present study, by using three different murine models of allergy, we have unambiguously shown for the first time that byakkokakeishito exhibited significant anti-allergic activities. It has been reported that byakkokaninjinto, another kampo formula containing gypsum, ameliorated symptoms of atopic dermatitis and inflammation in mice $[5,13]$. The suppressive effect of byakkokaninjinto 
Fig. 3 Effect of byakkokakeishito extracts $(B K T s)$ on the ear swelling of $\mathrm{NC} / \mathrm{Jic}$ mice topically treated with mite antigen. Time course of ear swelling in the $\mathrm{NC} / \mathrm{Jic}$ mice (a), its area under the curve (AUC) for 17 days (b), and serum IgE levels on day 17 (c) are shown. The daily dose of BKT15 $(0.90 \mathrm{~g} / \mathrm{kg})$ corresponds to ten times that of the human daily dose. Each column represents mean \pm S.E. of 8 mice. ${ }^{*} p<0.05$ vs. control by Bonferroni/Dunnett's multiple $t$ test

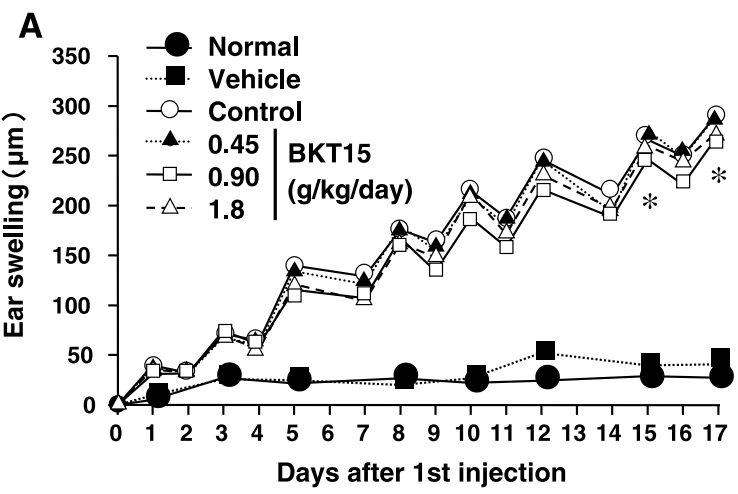

B

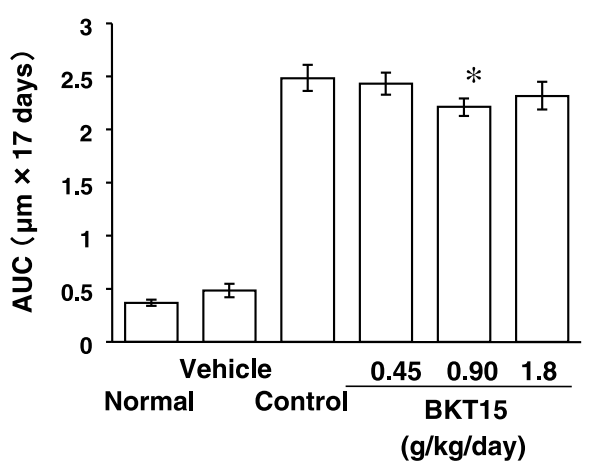

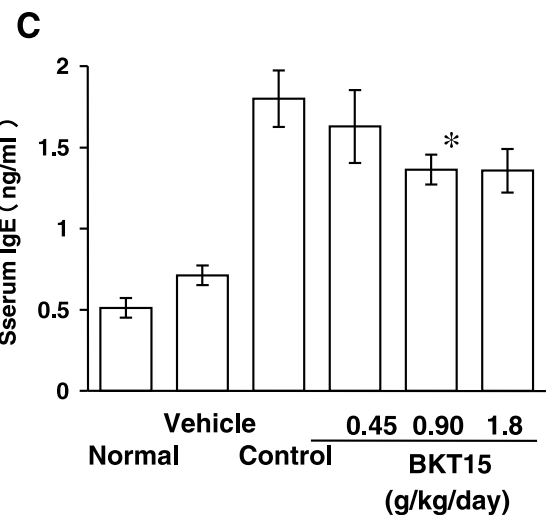

on IgE-mediated triphasic skin reaction in mice disappeared when byakkokaninjinto prepared without gypsum was administered [5]. These results may indicate that gypsum participates in the anti-allergic effects of the kampo formulas. Therefore, we evaluated how the antiallergic activity of BKT in the animal model is affected by changing the amount of gypsum in BKT.

In the PCA reaction model, the anti-allergic effect of BKT was significantly augmented by increasing the amount of gypsum. This effect of gypsum may be due to the increased extraction of low-molecular-weight organic compounds from other crude drugs prescribed in BKT together with gypsum. In fact, the concentration of Ephedra alkaloids of makyokansekito, a kampo formula comprising gypsum, Ephedra Herb, Armenia Seed, and Glycyrrhiza, was significantly decreased when prepared without gypsum [7]. However, in the present investigation neither the HPLC profiles nor the timosaponin A-III content in BKT was affected by the amount of gypsum in the formula.

Some physicians believe that there is no benefit in increasing the gypsum dosage to more than $20 \mathrm{~g} /$ day in the prescription because calcium concentration in water reaches saturation at this dosage [14]. However, the present study revealed that the calcium concentration in BKT was increased dose-dependently up to at least $60 \mathrm{~g} /$ day of gypsum when the crude drugs were boiled in $600 \mathrm{ml}$ water, and the concentration did not reach the saturation level. The increased calcium concentration in BKT may have enhanced the anti-allergic effect of BKT in the PCA reaction when the amount of gypsum was increased. It has been reported that calcium promotes passive transport of drugs through the intestinal epithelial membrane in rats [15]. Mace et al. [16] revealed that a high calcium concentration in the intestinal lumen induces glucose transporter 2 (GLUT2) insertion into the apical membrane of intestinal endothelial cells and stimulates glucose absorption in a rat jejunal loop model. It is suggested that some types of glycosides in plant materials might pass through the intestinal membrane passively via GLUT2 [17]. In BKT, calcium may promote intestinal absorption of some anti-allergic compounds derived from the four other prescribed crude drugs forming BKT, apart from gypsum.

Increasing the amount of gypsum did not affect the antiallergic activity of BKT in the contact dermatitis model or the mite antigen-induced atopic dermatitis model. In the PCA reaction model, the drug was administered to mice as a single dose $2 \mathrm{~h}$ before antigen challenge, and dye efflux was estimated. In contrast, in the other two models, BKT was administered to mice once a day for 9 days (contact dermatitis model) or 23 days (mite antigen-induced atopic dermatitis model), and anti-allergic activity was evaluated about $24 \mathrm{~h}$ after the previous administration of BKT. 
A ช

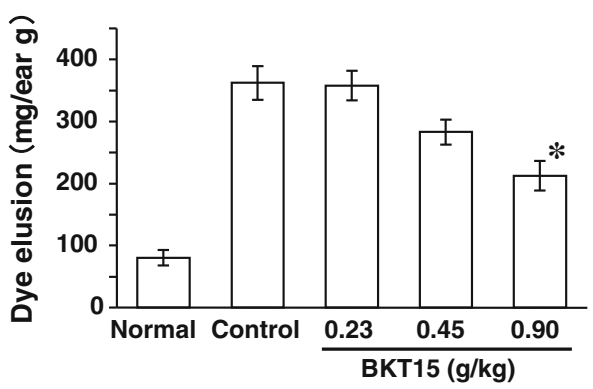

B
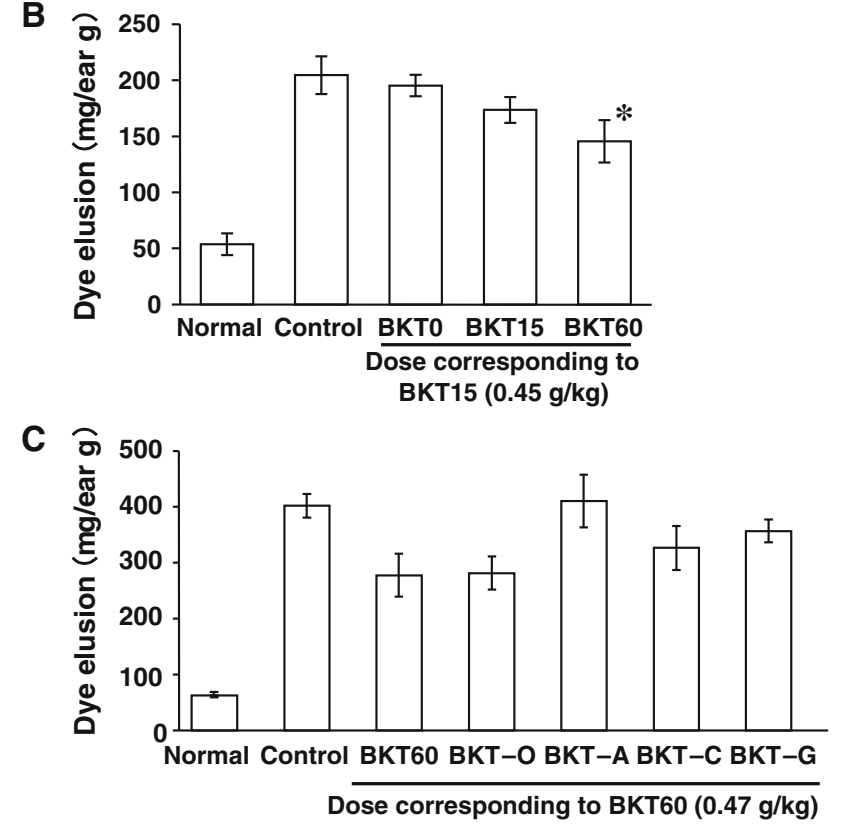

D

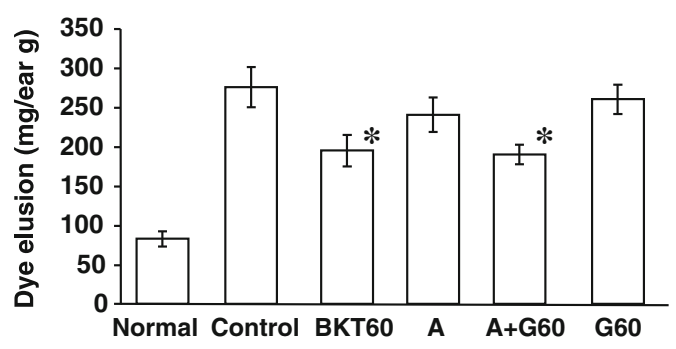

Fig. 4 Effect of byakkokakeishito extracts (BKTs) on the PCA reaction in ddY mice. Dose-dependent suppressive effects of BKT15 on the PCA reaction were evaluated (a). The daily dose of BKT15 $(0.45 \mathrm{~g} / \mathrm{kg})$ corresponds to five times that of the human daily dose. The suppressive effects of modified BKT samples shown in Table 1 on the PCA reaction at the dose corresponding to the dose of BKT15 $(0.45 \mathrm{~g} / \mathrm{kg})$ were evaluated (b). The suppressive effects of modified BKT samples shown in Table 2 on the PCA reaction at the dose corresponding to the dose of BKT60 $(0.47 \mathrm{~g} / \mathrm{kg})$ were evaluated (c and d). Each column represents mean \pm S.E. of 7 or 8 mice. $* p<0.05$ vs. control by Bonferroni/Dunnett's multiple $t$ test

Therefore, the blood concentration of active ingredients in BKT at the evaluation of the activity in the latter two models would be stable and at a lower level than that in PCA reaction model. Hence, the promotion of intestinal absorption of active ingredients by the increased calcium concentration might not affect the blood concentration at the time of evaluation in the latter two models, whereas in the PCA reaction model, increased intestinal absorption of the active compounds by calcium might lead to elevated blood concentrations of the active ingredients and thereby to enhanced anti-allergic activity of BKT.

The modified BKT samples prepared without Anemarrhena Rhizome or gypsum did not show significant antiallergic effects in the PCA model. Furthermore, the extract prepared by decocting a mixture of these two crude drugs exhibited an anti-allergic effect comparable to that of BKT, but neither Anemarrhena Rhizome nor gypsum alone exhibited this activity. These results suggest that some of the constituents derived from Anemarrhena Rhizome participate in the anti-allergic effects of BKT, and that calcium derived from gypsum would enhance the suppressive effect of BKT probably by enhancing intestinal absorption of the constituents. Lee et al. [18] estimated anti-allergic effects of several steroidal saponins isolated from Anemarrhena Rhizome and demonstrated that timosaponin A-III exhibits inhibitory activity in the PCA reaction and pruritus. We have shown in the present investigation that the timosaponin A-III content did not differ between BKT samples containing different gypsum contents. It would be interesting to examine whether gypsum promotes intestinal absorption of timosaponin A-III, and this awaits further investigation.

In conclusion, BKT exhibits an anti-allergic effect in several murine models. This may provide experimental evidence for the clinical use of BKT in allergic diseases. Gypsum may augment the anti-allergic activity of BKT, presumably by increasing intestinal absorption of Anemarrhena Rhizome-derived active constituents.

Acknowledgments The authors are grateful to Dr. Sumio Imai, Mr. Nobuyoshi Goto, and Mr. Hideaki Tani for providing us with the interesting clinical case successfully treated with BKT.

\section{References}

1. The Society of Japanese Pharmacopoeia (2012) The Japanese pharmacopoeia, Sixteenth Edition (JP XVI) edn. Yakuji-Nippo, Tokyo

2. Bensky D, Barolet R (1990) Chinese herbal medicine: formulas and strategies. Eastland Press, Seattle

3. Ikarashi N, Ogiue N, Toyoda E, Kon R, Ishii M, Toda T, Aburada T, Ochiai W, Sugiyama K (2012) Gypsum fibrosum and its major component $\mathrm{CaSO}_{4}$ increase cutaneous aquaporin-3 expression levels. J Ethnopharmacol 139:409-413

4. Yuan D, Sunouchi H, Sakurai T, Saito K, Kano Y (1998) Pharmacological properties of traditional medicines. XXVII. Interaction between Ephedra herb and Gypsum under hyperthermal conditions in rats. Biol Pharm Bull 25:872-874

5. Tatsumi T, Yamada T, Nagai H, Terasawa K, Tani T, Nunome S, Saiki I (2001) A Kampo formulation: Byakko-ka-ninjin-to (BaiHu-Jia-Ren-Sheng-Tang) inhibits IgE-mediated triphasic skin 
reaction in mice: the role of its constituents in expression of the efficacy. Biol Pharm Bull 24:284-290

6. Sakakibara I, Terabayashi S, Kubo M, Higuchi M, Sasaki H, Okada M (1999) Evaluation of Gou-teng (Hooks and Stems of Uncariae plants) III. Hypotensive principle from Uncaria rhynchophylla and alteration of its content on extraction process. Nat Med 53:308-312

7. Nakamura R, Makino B, Endo Y, Sakakibara I, Terabayashi S, Takeda S, Sasaki H (2006) Investigation of the role of a mineral crude drug in kampo medicine (Part I). Chemical analysis of multiple effects of Gypsum figrosum in makyokansekito. Nat Med 60:59-67

8. Imai S, Goto N, Tani J, Fujimura Y, Miyawaka F, Mizutani K, Makita K, Makino T, Mizukami H (2008) Discussion of sekko content in bakkokaishito. Jpn J Orient Med. 59: Sup 129 [Abstract]

9. Ootsuka K, Yakazu D (1966) Prescribers' formulary in Kampo medicines. Idoh No Nihon, Tokyo

10. Yamashita H, Michibata Y, Mizukami H, Ogihara Y, Morita A, Nose M (2005) Dermal mast cells play a central role in the incidence of scratching behavior in mice induced by multiple application of the hapten, 2,4,6-trinitrochlorobenzene. Exp Dermatol 14:438-444

11. Makino T, Hamanaka M, Yamashita H, Mizukami H (2008) Effect of bakumijiogan, an herbal formula in traditional Chinese medicine, on atopic dermatitis-like skin lesions induced by mite antigen in NC/Jic mice. Biol Pharm Bull 31:2108-2113
12. Makino T, Furuta A, Fujii H, Nakagawa T, Wakushima H, Saito K, Kano Y (2001) Effect of oral treatment of Perilla frutescens and its constituents on type-I allergy in mice. Biol Pharm Bull 24:1206-1209

13. Tohda C, Sugahara H, Kuraishi Y, Komatsu K (2000) Inhibitory effect of Byakko-ka-ninjin-to on itch in a mouse model of atopic dermatitis. Phytother Res 14:192-194

14. Watanabe K, Akiba T, Irie Y, Watanabe K, Protonicof G, Nishimura K, Ide Y (2010) Shinseiki-ni-yomu "Kampo-shinryo 30-nen". J Kampo Med 57:1131-1138

15. Rao JP (2009) Influence of dietary calcium content on intestinal permeability in rat. Ind J Med Res 129:681-684

16. Mace OJ, Morgan EL, Affleck JA, Lister N, Kellett GL (2007) Calcium absorption by Cav1.3 induces terminal web myosin II phosphorylation and apical GLUT2 insertion in rat intestine. J Physiol 580:605-616

17. Faria A, Pestana D, Azevedo J, Martel F, de Freitas V, Azevedo I, Mateus N, Calhau C (2009) Absorption of anthocyanins through intestinal epithelial cells: putative involvement of GLUT2. Mol Nutr Food Res 53:1430-1437

18. Lee B, Trinh HT, Jung K, Han SJ, Kim DH (2010) Inhibitory effects of steroidal timosaponins isolated from the rhizomes of Anemarrhena asphodeloides against passive cutaneous anaphylaxis reaction and pruritus. Immunopharmacol Immunotoxicol $32: 357-363$ 